\title{
PRE-WINTER FATTENING AND FAT LOSS DURING WING MOULT: THE ANNUAL CYCLE OF FAT DEPOSITION IN CAPTIVE BARNACLE GEESE (BRANTA LEUCOPSIS)
}

Steven J. Portugal ${ }^{1 *}$, Rona A. McGill ${ }^{2}$, Jonathan A. Green ${ }^{3}$ and Patrick J. Butler ${ }^{3}$

${ }^{1}$ Department of Biological Sciences, Royal Holloway University of London, Egham, Surrey, TW20 0EX

${ }^{2}$ SUERC, University of Glasgow, Glasgow, G12 8QQ

${ }^{3}$ School of Biosciences, University of Birmingham, Edgbaston, Birmingham, B15 2TT

*To whom correspondence should be addressed. Email: Steve.Portugal@rhul.ac.uk 


\begin{abstract}
Many different physiological changes have been observed in wild waterfowl during the flightless stage of wing moult, including a loss of body mass. Previously we established that captive barnacle geese (Branta leucopsis) underwent this characteristic decrease in body mass during their wing moult, even though they had unlimited and unrestricted access to food. In the present study we aimed to determine if this body mass loss during moult comprised mainly a reduction in fat stores, and to ascertain if the captive geese undergo pre-migratory and pre-winter fattening over a similar temporal scale to their wild conspecifics. The non-destructive technique of deuterium oxide isotope dilution was employed to provide repeated measurements of estimated fat deposition from a captive flock of fourteen barnacle geese. Birds were injected with deuterium oxide at 7 distinct intervals for one annual cycle. During the flightless period of the moult, body fat decreased by approximately $40 \%$ from the pre-moult value. During late-September and early October, body fat reached its highest point in the annual cycle, both as an absolute value and as a percentage of total body mass. We propose that while the energetic cost of wing moult is not the ultimate cause of fat loss in moulting barnacle geese, the approximate $212 \mathrm{~g}$ of fat catabolised during moult would provide sufficient energy to cover the cost of the replacement of the flight feathers, estimated to be $6384 \mathrm{~kJ}$, over an approximate 42 day period. We conclude that the previously recorded increase in metabolism during moult in the geese, led to the use of endogenous fat reserves because the birds reduced rather than increased their food intake rates owing to the increased risk of predation when flightless. We also conclude that captive barnacle geese do undergo
\end{abstract}


bioRxiv preprint doi: https://doi.org/10.1101/2020.04.26.062364; this version posted April 27, 2020. The copyright holder for this preprint (which was not certified by peer review) is the author/funder. All rights reserved. No reuse allowed without permission.

pre-winter and pre-migratory fattening, providing further evidence of the innate nature of these fat deposition cycles. 


\section{Introduction}

Fat is the primary energy store in birds, and the benefits of fat storage have been widely addressed with respect to the quantity, composition and morphological distribution of fat stored (Blem, 1990; Witter et al., 1993). Benefits of fat storage include insulation, mechanical support, protection, buoyancy in aquatic birds and both sexual and social signals. Of most importance, however, is the energy it liberates when metabolised, and it is the most energy-dense substrate in the body (Blem, 1990). Birds utilise fat most during periods of energy deficit, such as during migration, reproduction and moult (Dawson et al., 2000).

Geese, like the majority of avian herbivores in the Northern hemisphere, breed in the Arctic and winter in Southern, more temperate areas (Van der Graaf et al., 2007; Bonier et al., 2007). Being capital breeders, geese have to balance their energy expenditure and food intake throughout the winter months and early spring, to be able to migrate northwards and to breed successfully (van der Graaf et al., 2007, Clausen et al., 2003). In barnacle geese, Branta leucopsis, birds with larger fat stores have been shown to breed more successfully, suggesting fat accumulation during the non-breeding season is central to increasing fitness in this species (Cope, 2003; Portugal et al., 2011a; Portugal et al., 2011b). Once breeding has been completed, the geese must replace their feathers (i.e. moult) and accumulate sufficient fat reserves for the autumn migration, before climatic conditions on the Arctic tundra deteriorate (Bonier et al., 2007). These events all require 
energy and thus either the utilisation of fat reserves and/or an increase in food intake (hyperphagia).

Waterfowl are part of one of eight orders of birds that undergo a post-breeding simultaneous flight feather moult, rendering them flightless for a period of approximately 15-45 days (Woolfenden, 1967, Hohman et al., 1992; Guillemette et al., 2012). Studies on wild waterfowl have demonstrated that during this wing moult period, birds lose body mass (Geldenhuys, 1983; Sjöberg, 1986; Van der Jeugd et al., 2003; Portugal et al., 2009a; Portugal et al., 2009b), alter their behaviour (Kahlert et al., 1996; Adams et al., 2000; ; Portugal et al. 2010; Martin and Portugal, 2011) and significantly increase their rate of metabolism (e.g. Guozhen and Hongfa, 1986; Portugal et al., 2007; Portugal et al., 2019a). Fox and Kahlert (2005) illustrated in greylag geese, Anser anser, for example, the majority of this mass loss during moult was a result of a depletion of fat reserves, which they proposed the geese used to meet the shortfall in normal daily energetic requirements (i.e. these stores were expended to supplement exogenous sources of energy in the diet).

Recent work on captive barnacle geese has shown that, despite having constant access to food and exposure to no predators, they respond in a similar way both physiologically and behaviourally to wing moult as their wild conspecifics (Portugal et al., 2007). The geese lose approximately $25 \%$ of their body mass during the flightless phase, and their rate of resting metabolism increases by $80 \%$ compared to non-moult values. Behaviourally, the birds responded to wing moult by significantly increasing their time dedicated to resting, and decreasing the time spent involved in locomotion and foraging 
(Portugal et al., 2007). Looking at the annual cycle of body mass as a whole, of particular note was the increase in body mass in the captive geese during September and early October, coinciding with the pre-migratory and pre-winter fattening period in wild barnacle geese (Portugal et al, 2007; Owen et al., 1992). Biebach (1996) noted that so far it has been impossible to get captive animals to fatten before the onset of winter, indicating that under the conditions of captivity, factors are missing that, under natural conditions, induce the accumulation of body fat. So far, only year-round body mass has been measured in captive barnacle geese, therefore, it is not certain to what extent periods of mass loss and mass gain are the result of changes in body fat content.

The isotope dilution method is one of the most frequently used non-destructive techniques for determining body composition (Speakman et al, 2001). Water is not evenly distributed in body tissues, and proteinaceous tissue contains substantially more water than fat (Speakman et al., 2001). Isotope dilution predicts the total body water content by dilution of a stable isotope, and then estimates the total fat content based on the inverse relationship between body fat and body water (Robbins, 1993; Speakman et al., 2001; Mata et al., 2005). Previously (Portugal 2008), we have demonstrated that, with the appropriate calibration and corrections applied, deuterium oxide isotope dilution can give sufficiently accurate predictions of body fat in captive barnacle geese to study the temporal changes in the 'population mean' of a group of birds.

The primary aim of this study was to document year-round total body fat in captive barnacle geese, to establish whether captive birds would follow a similar temporal pattern 
of fat deposition to that of their wild conspecifics. We also aimed to determine if (a) the geese would deposit fat prior to wing moult, to enable a reduction in foraging and locomotor activities during the vulnerable flightless phase by relying on endogenous fat stores (b) the body mass loss observed in moulting captive geese is primarily a result of a depletion in fat (c) captive geese would deposit fat during September and early October to coincide with pre-migratory and pre-winter fattening in their wild conspecifics.

\section{Materials and Methods}

\section{Birds and sampling protocol}

A captive population of 14 barnacle geese obtained as 3-week old goslings was maintained under natural light in large outdoor aviaries at the University of Birmingham. The goslings were obtained from Bentley Waterfowl Park (Sussex, UK) which has held a self-sustaining captive population of this species since 1982. The geese were fed with a 50-50 diet (Lilico, Surrey, UK) of mixed poultry corn (4\% fat, $12 \%$ protein and $71 \%$ carbohydrate) and poultry growers pellets (3\% fat, 16\% protein and $61 \%$ carbohydrate), and water was available ad libitum.

To provide estimates of body fat content from periods of relatively stable body mass and periods of body mass change, sampling periods were selected based on year round body mass data collected from the same captive flock of barnacle geese the previous year (Portugal et al., 2007). Birds were sampled in February $(\mathrm{n}=7)$, March $(\mathrm{n}=14)$, June $(\mathrm{n}=$ 
11), July $(n=5)$, August $(n=5)$, October $(n=7)$ and December $(n=5)$, of 2005. Birds were sampled at approximately the same time of day (09:00 - 12:00 GMT) to control for any natural daily rhythms and minor changes in body mass and fat content (Speakman et al., 2001). Sample numbers vary because of samples drying out while in capillaries and storage.

Isotope dosage and administration

For each goose, food was withheld for 7 hours prior to deuterium oxide $\left(\mathrm{D}_{2} \mathrm{O}\right.$, SigmaAldrich, 99.98\%) administration and the sampling of blood for $\mathrm{D}_{2} \mathrm{O}$ analysis.

$\mathrm{D}_{2} \mathrm{O}$ dosage was calculated using equation 12.1 from Speakman (1997);

$$
\text { dosage }=\{0.65(\text { body mass }(\mathrm{g}) \times \mathrm{DIE}\} / \mathrm{IE}
$$

where the constant, 0.65 , is the approximate proportion of the body comprised of water, DIE is the desirable initial enrichment ( $\mathrm{ppm})$ and IE is the injectate enrichment (ppm). Birds were weighed to the nearest $5 \mathrm{~g}$. Blood samples were taken from either the brachial or intertarsal vein for determination of background enrichment of $\mathrm{D}_{2} \mathrm{O}$, immediately prior to $\mathrm{D}_{2} \mathrm{O}$ administration. A disposable $1 \mathrm{ml}$ syringe (Terumo) fitted with a 24-gauge stainless steel hypodermic needle was used for administration of the $\mathrm{D}_{2} \mathrm{O}$, via an intraperitoneal injection into the lower abdomen. $\mathrm{D}_{2} \mathrm{O}$ was injected slowly and the needle left in for five seconds, to avoid any injectate seeping out (Speakman et al., 2001). The actual amount of $\mathrm{D}_{2} \mathrm{O}$ injected was accurately determined by weighing the syringe to the nearest 
$0.0001 \mathrm{~g}$ before and after injection. Subsequent blood samples were collected $90 \mathrm{~min}$ after administration of the $\mathrm{D}_{2} \mathrm{O}$, based on pilot data showing that $90 \mathrm{~min}$ was an appropriate length of time for the isotope to equilibrate (Portugal 2008). Blood samples were drawn up in $50 \mu \mathrm{L}$ non-heperinised glass capillaries (Vitrex, Cambridge, UK) and immediately shaken to the centre of the capillary, which was flame sealed with a butane gas torch (Radio Spares, Corby, UK) and then wax sealed. Capillaries were then stored in an air-tight container.

\section{Calculation of ${ }^{2} H$ dilution space}

Isotope dilution space was calculated by the plateau method (Halliday and Miller, 1977), using equation 4 of Speakman et al. (2001);

$$
N_{m o l}=\frac{M_{m o l}\left(E_{i n}-E_{p}\right)}{\left(E_{p}-E_{b}\right)}
$$

where $\mathrm{N}_{\text {mol }}$ is the molar quantity of water present in the body, $\mathrm{E}_{\mathrm{in}}$ is the enrichment of the material introduced into the animal, $\mathrm{M}_{\text {mol }}$ the molecular weight of the $\mathrm{D}_{2} \mathrm{O}, \mathrm{E}_{\mathrm{b}}$ is the background enrichment of this material in the animal, and $E_{p}$ the enrichment measured after the 'dispersal' process is completed.

Assuming the constancy of the water content of the lean body mass (LBM; Pace and Rathbun, 1945), estimates of body composition could be obtained as follows: 


$$
\begin{aligned}
& \% L B M=\frac{\% T B W}{w}, \\
& \% \mathrm{TBF}=100-\% \mathrm{LBM},
\end{aligned}
$$

where total body fat (TBF), total body water (TBW) and LBM were expressed as a percentage of fresh body mass. Here, $w$ is the mean fractional water content of LBM for nine captive geese that were sampled destructively $(0.731 \pm 0.013$, Portugal 2008).

TBW determined via $\mathrm{D}_{2} \mathrm{O}$ dilution (hereafter referred to as $T B W \mathrm{D}_{2} \mathrm{O}$ ) was corrected (e.g. Mata et al., 2005) using the relationship between TBW $\mathrm{D}_{2} \mathrm{O}$ and TBW obtained through desiccation (hereafter referred to as TBW DES), before TBF was determined. This correction factor was achieved through calibrating the two (Portugal 2008). The relationship between TBW DES and TBW $\mathrm{D}_{2} \mathrm{O}$ was significantly different between the two sexes, and thus TBW $\mathrm{D}_{2} \mathrm{O}$ for each sex was corrected as follows:

F: TBW Corrected $(\mathrm{g})=0.25 \times \mathrm{TBW} \mathrm{D} 2 \mathrm{O}+1180$

M: TBW Corrected $(g)=1.62 \times \mathrm{TBW} \mathrm{D}_{2} \mathrm{O}+104$

Isotope analysis

$\mathrm{D}_{2} \mathrm{O}$ enrichment was measured using a chromium reduction furnace interfaced with a dual-inlet isotope-ratio mass spectrometer (Donnelly et al., 2001), at the Scottish 
Universities Environmental Research Centre (SUERC), East Kilbride. Water was extracted from the blood samples by vacuum lyophilisation. Laboratory water standards were also prepared in the same way to correct for day-to-day variations in the performance of the vacuum line. Samples and standards were collected in $50 \mu \mathrm{L}$ nonheperinised glass capillaries, shaken to the centre of the capillary, and flame sealed with an acetylene torch. Capillaries were broken and the extracted water was then injected in to the mass spectrometer (VG Optima) (after Donnelly et al., 2001). Each batch of samples was analysed with triplicates of three laboratory standards, waters of known isotope composition (calibrated relative to SLAP, SMOW and GISP international water standards). These lab standards perform a dual purpose to both correct the isotope ratio of the sample relative to the international standards and to correct for daily mass spectrometer drift, and day-to-day variations in the performance of the mass

spectrometer. Isotopically characterised $\mathrm{H}_{2}$ gas was used in the reference channel. All isotope enrichments were measured in delta (per mil) relative to the reference gas and those values are in turn calibrated by the laboratory standards, and converted to ppm using established ratios for the reference materials. Measures of isotope enrichment were based on independent analysis of at least two sub-samples of the water extracted from the blood samples.

Statistical analysis

Since TBW $\mathrm{D}_{2} \mathrm{O}$ was corrected using the calibration relationship between $T B W \mathrm{D}_{2} \mathrm{O}$ and TBW DES, estimates of meant TBW and hence TBF are presented \pm the standard error of 
the estimate (SEE, Zar, 1984). Estimates of fat content were compared using Woolf's test for differences with Bonferonni corrected proximate normal test (Z-test) post-hoc comparisons (e.g. Green et al., 2002).

\section{Results}

Body mass changed significantly throughout the annual cycle (Fig. 1a, ANOVA, $P<$ 0.001). Estimated total body fat content of the captive barnacle geese changed significantly between the seven sampling sessions (Fig. 1b, Woolf's test for equality, $\chi^{2}=$ 68.8, $P<0.0001)$. Further $Z$-tests, with Bonferonni corrections, between the seven sampling sessions showed that total body fat content during wing moult in August (129.9 $\pm 22.4 \mathrm{~g}$ ) was significantly lower than each of the other six sampling sessions. Between early July and mid-August, the geese lost approximately $212 \mathrm{~g}$, or $40 \%$, of body fat over a 5-week period, an average daily fat loss of $6 \mathrm{~g}$. Fat content was at its highest in the autumn, where estimated fat content peaked at $352.1 \pm 20.9 \mathrm{~g}$. Consequently, over the 42 days between the August and October sampling sessions, the geese gained, on average, approximately 5.2 g per day. Body fat decreased steadily during the winter months, with total body fat values of $234.1 \pm 23.4 \mathrm{~g}$ and $189.5 \pm 24.9 \mathrm{~g}$ being recorded for December and February respectively (Fig. 1b). Fat content in February represented a 53\% decrease on body fat at the start of the non-breeding season in October, and fat content was significantly lower in February than both July and October. Between February and March $(280.9 \pm 17.1 \mathrm{~g})$, body fat increased by approximately $91 \mathrm{~g}$, before reaching a peak just prior to wing moult in July $(342.5 \pm 36.6 \mathrm{~g})$. Fat as a percentage of body mass followed a 
similar pattern to that of actual fat mass (Fig. 1c), with body fat percentage ranging from $20.2 \%$ in October to just $8.3 \%$ in August.

\section{Discussion}

Fat loss during wing moult

Despite constant access to food, the captive barnacle geese lost approximately $212 \mathrm{~g}$ of body fat during the wing moult period, equivalent to $40 \%$ of their fat reserves in comparison to pre-moulting levels in July. By the end of wing moult in mid-August, body fat only constituted on average $8 \%$ of the bird's total body mass, compared to $16 \%$ and $22 \%$ pre-and post- wing moult. Fox and Kahlert (2005) recorded a loss of $268 \mathrm{~g}$ of fat on average in wild moulting greylag geese, however, no changes in fat content during moult have been identified in mallard Anas platyrhynchos, great-crested grebe Podiceps crisatus, common scoter Melanitta nigra or lesser scaup Aythya affinis (Young and Boag, 1982; Piersma, 1988; Fox et al., 2008; Austin and Fredrickson, 1987).

Depletion of fat stores during moult in wild birds, like body mass loss, has been interpreted to be a result of nutritional stress caused by the regrowth of the feathers (e.g. Hanson, 1962), a response to the increased risk of predation brought about by being flightless (e.g. Panek and Majewski, 1990) and an adaptation to regain flight quicker on partially regrown flight feathers (e.g. Owen and Ogilvie, 1979). Previously, we concluded 
that in barnacle geese at least, mass loss (and thus fat loss in this instance) was a consequence of the $80 \%$ increase in metabolism during moult, coupled with the reduction in time spent foraging, causing a decrease in body mass (Portugal et al., 2007). Therefore, the proximate cause of fat loss is likely to be the interaction of the decrease in food intake and the increase in metabolic rate as a result of feather synthesis. However, the ultimate cause of fat loss in wild birds is the increased risk of predation brought about by the bird's flightless state, restricting the ability to forage, meaning the geese are not able to increase their food intake to counteract the observed increase in metabolism. As a result, they must rely on their endogenous fat reserves during the flightless phase of moult.

Further evidence that this change in behaviour and subsequent loss of body fat is a product of flightlessness and the increased risk of predation, stems from the increase in body mass and body fat in July just prior to wing moult. At this stage, the captive geese were undergoing their annual body moult, which stretched over a period of approximately 90 days between July and September. Despite regrowing heavier body feathers at this time (e.g. Panek and Majewski, 1990), the geese were gaining body fat, suggesting the cost of regrowing feather alone is not sufficient to result in a loss of body fat.

Although most of species of duck studied do not lose significant amounts of fat during wing moult, certain species of geese have been shown to (Hohman et al. 1992). Therefore, it seems likely that there is a link between foraging style, food type and fat loss during moult, and choice of moult site. Many species of duck can continue foraging throughout the duration of moult, as their food source is obtained either from the surface, 
or under the water, where the birds are relatively safe. Moulting barnacle geese in the Arctic rely on vegetation that is not found in water, and can often be some distance from a water body (Owen and Ogilvie, 1979). Therefore, for the geese, resting on or beside water for safety is frequently mutually exclusive with productive foraging. The fat, and hence and body mass, increases just prior to moult are likely to serve a dual function of enabling the geese to reduce foraging when flightless and rely on endogenous reserves, while increasing the rate of feather synthesis during moult as more reserves are available for this, thus potentially shortening the flightless period - this has been suggested as the possible cause of mass increase prior to wing moult in some duck species (e.g. van Weetering and Cooke, 1999).

Potentially, geese may be able to build large fat stores prior to moult because of their larger size. For example, in coots and grebes, structurally larger individuals can survive longer without food, while being able to deposit larger fat stores (Biebach, 1996). It may be that ducks, being smaller, are unable to deposit sufficient fat stores, and therefore must continue foraging while flightless, albeit at a reduced level (e.g. Adams et al., 2001).

Fox and Kahlert (2005) described body mass and fat loss in moulting greylag geese as a representation of the nutritional or energetic "stress" of wing moult, and proposed it to be a further example of avian phenotypic plasticity. This trait enables the geese to meet a nutritional or energetic shortfall from endogenous reserves, in a way that may not necessarily be related to direct fitness costs. Therefore, the barnacle geese show adaptive fat gain prior to wing moult, and the accumulation of fat stores will enable the geese to 
exploit habitats that are predator free, but which perhaps do not provide the required levels of exogenous nutrient or energy to sustain them through moult.

Does fat catabolism cover the cost of moult?

The captive geese lost approximately $200 \mathrm{~g}$ of fat during late July and August. Although it is unlikely that the energetic cost of wing moult is the ultimate cause of body mass loss in moulting waterfowl, the increase in metabolism coupled with a decrease in foraging work together to cause a loss in body mass, and in this instance, a depletion of fat stores. Using simple calculations it is possible to calculate what the cost of wing moult in the geese would be, and to see if the fat catabolised would provide sufficient enegry to 'cover the cost' of the regrowth of the flight feathers.

Plumage mass of birds can be roughly approximated by the equation, plumage mass = $0.09 W^{0.95}$ (Turcek, 1966; Lindström et al., 1993; Murphy, 1996), and mass of plumage is typically around $6 \%$ of the total body mass (Turcek, 1966). As demonstrated in Portugal et al. (2007) captive barnacle geese have a large annual variation in body mass, therefore, the average mass for all geese for the month of April 2005 (when body mass is stable, average of $1.8 \mathrm{~kg}$ ) was used to determine approximate average plumage mass, and the value calculated was $112.37 \mathrm{~g}(6.1 \%$ of total body mass). With the associated mass of the feather sheath included (Murphy, 1996), the total plumage mass for a captive barnacle goose is $134.4 \mathrm{~g}$ (for comparison, Lindström et al., 1993, cited a plumage mass of $160.6 \mathrm{~g}$ 
for the larger greylag goose). Flight feathers typically account for about one-quarter to one-third of the total plumage mass (e.g. Newton, 1966). The midpoint of these two estimates would provide a value of $36.1 \mathrm{~g}$ for flight feathers alone for the captive barnacle geese, or $43.2 \mathrm{~g}$ including sheaths.

Using equation 3 of Lindström et al. (1993) it is possible to calculate the rate of feather production $\left(C_{\mathrm{f}}\right)$ if mass specific metabolic rate $\left(\mathrm{kJ} \mathrm{g}^{-1} \mathrm{~d}^{-1}\right)$ of the bird is known. Coupled with plumage mass, it is then possible to calculate the energetic cost of replacing all feathers, and thus the cost of moult. For the captive geese in the present study, rate of feather production was calculated to be $147.8 \mathrm{~kJ}$ (g dry feather) ${ }^{-1}$. $\mathrm{C}_{f}$ typically decreases with increasing body size, for example values reported in Lindström et al. (1993) demonstrated $26.6 \mathrm{~kJ}$ (g dry feather) ${ }^{-1}$ for the ostrich, Struthio camelus, and $780 \mathrm{~kJ}$ (g dry feather) $^{-1}$ for the goldcrest, Regulus regulus.

With the mass of flight feathers and the rate of $\mathrm{C}_{f}$ known, the overall cost of producing the flight feathers can be estimated to be $6385 \mathrm{~kJ}$, or $152 \mathrm{~kJ} \mathrm{~d}^{-1}$ for the approximate 42 day duration of wing moult (assuming feather growth is constant throughout a 24-hour period). If the energy density of fat is $39 \mathrm{~kJ} \mathrm{~g}^{-1}, 163 \mathrm{~g}$ of fat on average would be required to cover the 'cost' of re-growing the flight feathers. It is likely, therefore, that most of the $212 \mathrm{~g}$ of fat catabolised during the wing moult period was used to grow the new flight feathers. As foraging was greatly reduced (Portugal et al., 2007) during wing moult, it is likely the remaining $35 \mathrm{~g}$ or so of fat will contribute towards the shortfall in food intake. 
Pre-winter fattening

Body fat made up the highest percentage of total body mass $(21 \%)$ in late September early October, before decreasing in December and then reaching the lowest point of the year in February. Biebach (1996) commented that it had not been possible to get captive animals to fatten prior to winter, however, the high percentage of body fat in autumn in the captive geese suggests that this was the case in the present study. If body fat percentage following wing moult returned to a similar level to that of late spring and early summer (e.g. 15\%) it could be considered that body fat was returning to 'normal' fat levels after fat loss during wing moult. However, as post moult fat was higher both in percentage and absolute terms, it suggests that there is an element of pre-winter fattening taking place. This provides further evidence that captive geese undergo the same physiological changes as their wild conspecifics.

In the Svalbard population of wild barnacle geese, overall fat stores increased and then varied throughout the non-breeding season, with the rate of increase in fat stores being most rapid at the start and end of the non-breeding period (Cope, 2003). Owen et al. (1992) found that fat accumulated in wild barnacle geese during the autumn, followed by a significant decline throughout winter and an increase late spring. Phillips et al. (2003) noted that the geese depleted the most profitable feeding areas by around early December, after which they switched to less profitable feeding areas, and subsequently 
lost body fat. During the non-breeding season, peaks in abdominal profile indexes (Owen, 1981) occurred in October and November, with the lowest point coming in February.

The captive geese followed a similar pattern to the wild geese. This pattern suggests that fat levels and control of fat follows an endogenous cycle, being only slightly modified by environmental constraints. Owen et al. (1992) suggested that birds might lay down reserves in preparation for lean periods, and then only maintain sufficient reserves to guarantee against predictable adversity. It is possible therefore, that once the geese have arrived in Scotland and recovered their body fat reserves from their autumn migration, a loss of unnecessary reserves may be advantageous to reduce the risk of predation, as heavier birds are probably less agile (Portugal et al., 2011c).

The one highly unpredictable event for the geese will be the conditions on arrival on their wintering grounds in Scotland following migration. During spring migration the geese take roughly 4-5 weeks to reach their breeding grounds, essentially following the new growth of vegetation northwards (Cope, 2003; Portugal et al., 2019b). Fattening for the spring migration is also a two-step process, first on the Solway and then on Helgeland, a major staging area in Norway (Black et al., 1991). Here, fat reserves expended during the first part of the migration are at least partially replenished. In autumn however, geese migrate from Svalbard to Scotland in far shorter time, with some birds capable of achieving this is less than one week (Butler et al., 1998). Unlike the situation in spring, geese migrating in autumn do not know what conditions will be like on arrival at their destination. Therefore, large fat reserves are essential not only for migration but as an 
insurance for arrival at the wintering grounds, should conditions be adverse. Butler and Woakes (2002) demonstrated that wild barnacle geese undergo a period of seasonal hypothermia (or anapyrexia) in autumn thought to aid in fat deposition, not only prior to migration but for recovery of fat reserves once the wintering grounds are reached, again stressing the importance of pre-migratory and pre-winter fattening in this species.

In the present study we have demonstrated that captive barnacle geese do deposit fat reserves prior to wing moult, and that subsequently the majority of mass loss during the flightless phase of wing feather replacement is primarily a depletion of fat. In October, fat reserves in the geese increased significantly, suggesting that the birds were depositing fat, before the onset of winter.

\section{Acknowledgements}

Isotope work was possible thanks to a grant from NERC to use facilities at the SUERC. We would like to thank Jason Newton, Alison MacDonald and Terry Donnelly (SUERC) for their assistance with water extraction and equipment. We are grateful to Alan Gardner, Phil Archer, Ben Heanue and Pete Jones for looking after the geese. Thanks also to Craig White, David Gardiner, Alex Kabat, and Claire Tyler for holding birds during blood sampling sessions. 
bioRxiv preprint doi: https://doi.org/10.1101/2020.04.26.062364; this version posted April 27, 2020. The copyright holder for this preprint (which was not certified by peer review) is the author/funder. All rights reserved. No reuse allowed without permission. 


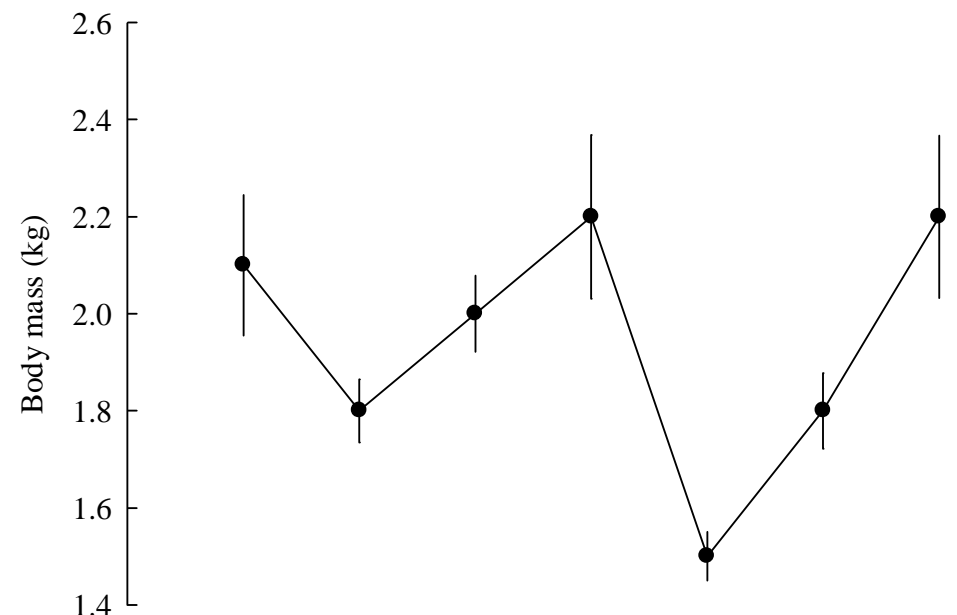

a)

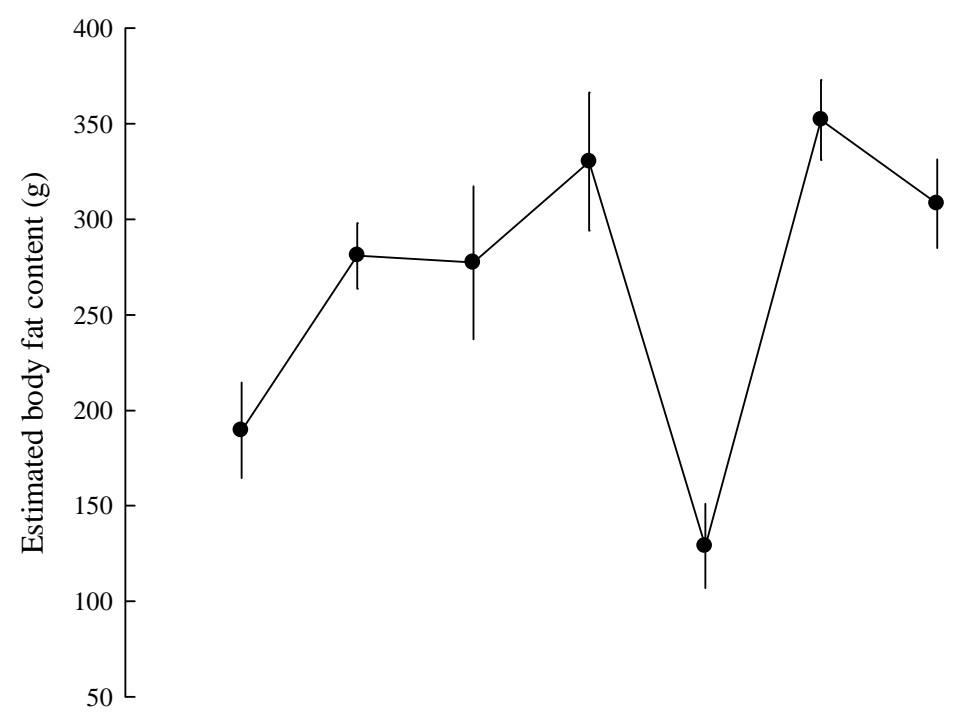

b)

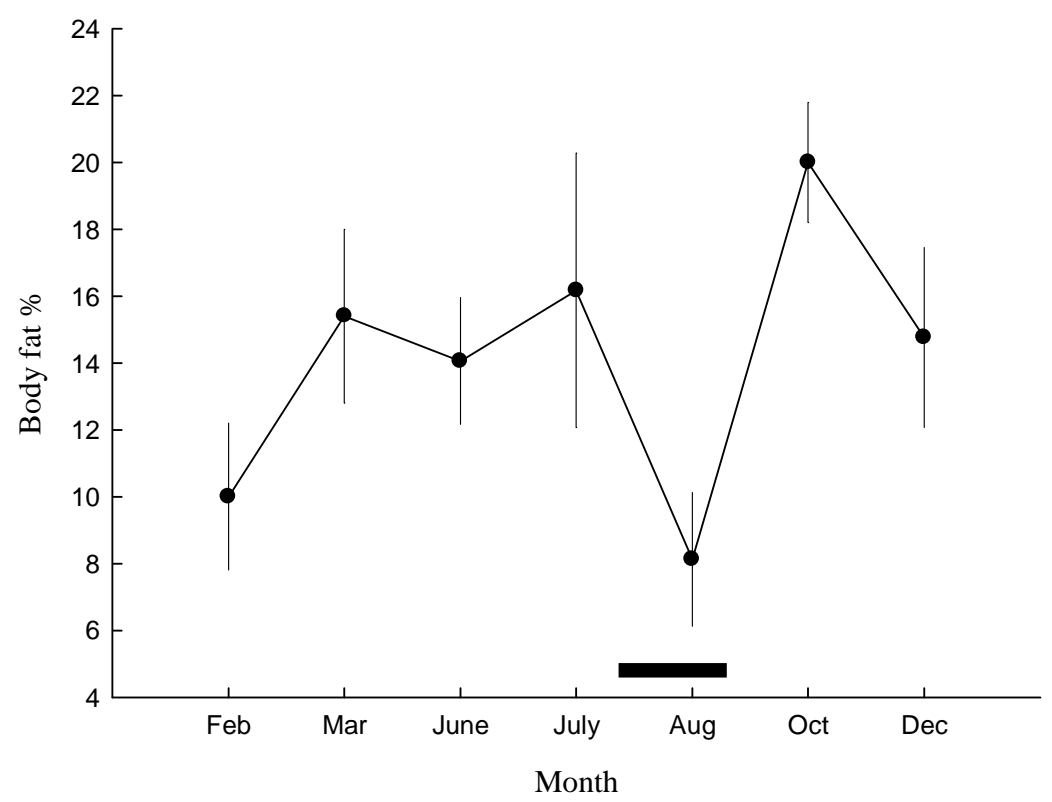

c) 
Figure .1: (a) Year-round body mass $( \pm$ SEM), (b) fat content $( \pm$ SEE) and (c) fat content as a $\%$ ( \pm confidence intervals) of total body mass, from captive barnacle geese. Fat content changed significantly throughout the annual cycle (Woolf's test for equality, $\chi^{2}=$ 68.8, $P<0.0001)$. Black bar represents approximate wing moult period. 


\section{References}

Adams, P. A., Roberson, G. J. and Jones, I. L. (2000). Time-activity budgets of harlequin ducks molting in the Gannet Islands, Labrador. Condor. 102: 703-708.

Austin, J. E. and Fredrickson L. H. (1987). Body and organ mass and body composition of postbreeding female lesser scaup. Auk. 104: 694-699.

Biebach, H. (1996). Energetics of winter and migratory fattening. In Avian Energetics and nutritional ecology, (ed. C. Carey): Chapman and Hall.

Black, J. M., Deerenberg, C. and Owen, M. (1991). Foraging behaviour and site selection of barnacle geese, Branta leucopsis, in a traditional and newly colonised spring stating habitat. Ardea. 79: 349-358.

Blem, C. R. (1990). Avian energy storage. Pp. 59-113 in Current Ornithology, vol. 7 (D. M. Power, Ed.). New York. Plenum Press.

Bonier, F., Martin, P. R., Jensen, J. P., Butler, L. K., Ramenofsky, M. And Wingfield, J. C. (2007). Pre-migratory life history stages of juvenile Arctic birds: costs, constraints, and trade-offs. Ecol. 88 (11): 2929-2735.

Butler, P. J., Woakes, A. J. and Bishop, C. M. (1998). Behaviour and physiology of Svalbard Barnacle Geese Branta leucopsis during their autumn migration. J. Avian Biol. 29: 536 - 545 .

Butler, P. J. and Woakes, A. J. (2001). Seasonal hypothermia in a large migrating bird: saving energy for fat deposition. J. Exp. Biol. 204: 1361 - 1367.

Clausen, P., Green, M. and Alerstam, T. (2003). Energy limitations for spring migration and breeding: the case of the brent geese Branta bernicla tracked by satellite telemetry to Svalbard and Greenland. Oikos. 103: 426-445.

Cope, D. R. (2003). Variation in daily and seasonal foraging routines of non-breeding barnacle geese (Branta leucopsis): working harder does not overcome environmental constraints. J. Zool. 260: 65-71.

Dawson, A., Hinsley, S.A., Ferns, P.N., Bonser, R.H.C. and Eccleston, A. (2000). Rate of moult affects feather quality: a mechanism linking current reproductive effort to future survival Proc. Roy. Soc. B. 267: 2093-2098. 
Dietz, M. W., Dekinga, A., Piersma, T. and Verhulst, S. (1999). Estimating organ size in small migrating shorebirds with ultrasonography: an intercalibration exercise. Physiol. Biochem. Zool. 72: 28-37.

Donnelly, T., Waldron, S., Tait, A., Dougans, J. and Bearhop, S. (2001). Hydrogen isotope analysis of natural abundance and deuterium-enriched waters by reduction over chromium on-line to a dynamic dual inlet isotope-ratio mass spectrometer. Rapid Commun. Mass. Spectrom. 15: 1297-1303.

Fox, A. D. and Kahlert, J. (2005). Changes in body mass and organ size during wing moult in non-breeding greylag geese Anser anser. J. Avian Biol. 36: 538-548.

Fox, A. D., Hartmann, P. and Petersen, I. K. (2008). Changes in body mass and organ size during moult in common scoter Melanitta nigra. J. Avian. Biol. 39: 35-40.

Geldenhuys, J. N. (1982). Morphological variation in wing-moulting South African Shelduck. Ostrich. 54: 19-25.

Green, J. A., Butler, P. J., Woakes, A. J. and Boyd, I. L. (2002). Energy requirements of female Macaroni Penguins breeding at South Georgia. Func. Ecol. 16: 671-681.

Guillemette, M. G., Richman, S. E., Portugal, S. J., \& Butler, P. J. (2012). Behavioural compensation reduces energy expenditure during migration hyperphagia in a large bird. Functional Ecology. 26: 876-883.

Guozhen, Q. and Hongfa, X. (1986). Molt and resting metabolic rate in the common teal Anas crecca and the shoveller Anas clypeata. Acta Zool. Sin. 32 (1): 73-84.

Halliday, D. and Miller, A. G. (1977). Precise measurement of total body water using trace quantities of deuterium oxide. Biomed. Mass Spectrom. 4: 82-87.

Hanson, H. C. (1962). The dynamics of conditions factors in Canada geese and their relation to seasonal stresses. Arct. Inst. N. Tech. Pap. No. 12.

Hohman, W. L., Ankney, C. D. and Gordon, D. H. (1992). Ecology and management of postbreeding waterfowl. In Ecology and management of breeding waterfowl, eds. B. D. J. Batt A. D. Afton M. G. Anderson C. D. Ankney D. H. Johnson J. A. Kadlec and G. L. Krapu), pp. 128-189. Minneapolis: University of Minnesota.

Kahlert, J., Fox, A. D. and Ettrup, H. (1996). Nocturnal feeding in moulting Greylag Geese Anser anser - an anti predator response? Ardea, 84: 15-22. 
Lindstrom, A., Visser, G. H. and Daan, S. (1993). The energetic cost of feather synthesis is proportional to basal metabolic rate. Physiol. Zool. 66, 490-510.

Martin, G. R. \& Portugal, S. J. (2011). Feeding ecology dictates visual field topography in Ibis and Spoonbills. Ibis. 153: 662-671.

Mata, A. J., Caloin, M., Robin, J. P. and Le Maho, Y. (2005). Reliability in estimates of body composition of birds: oxygen-18 versus deuterium dilution. Physiol. Biochem. Zool. 79 (1): 202-209.

Murphy, M. E. (1996). Energetics and nutrition of molt. In Avian Energetics and nutritional ecology, (ed. C. Carey): Chapman and Hall.

Newton, I. (1966). The moult of the Bullfinch Pyrrhula pyrrhula. Ibis. 108: 41-67.

Owen, M. and Ogilvie, M. A. (1979). The molt and weights of barnacle geese in Spitsbergen. Condor. 81: 42-52.

Owen, M. (1981). Abdominal profile - a condition index for wild geese in the field. $J$. Wild. Manag. 45: 227-230.

Owen, M., Wells, R. L. and Black, J. M. (1992). Energy budgets of wintering Barnacle Geese: the effects of declining food resources. Ornis Scand. 23: 451-458.

Pace, N. and Rathbun, E. N. (1945). Studies on body composition. III. The body water and chemically combined nitrogen content in relation to fat content. J. Biol. Chem. 158: 685-691.

Panek, M. and Majewski, P. (1990). Remex growth and body mass of mallards during wing moult. Auk. 107: 255-259.

Phillips, R. A., Cope, D. R., Rees, E. C. and Connell, J. O. (2003). Site fidelity and range size of wintering barnacle geese Branta leucopsis. Bird Study. 50: 161-169.

Piersma, T. (1988). Breast muscle atrophy and contraints on foraging during the flightless period of wing moulting great crested grebes. Ardea. 76: 96-106.

Portugal, S. J., Green, J. A. and Butler, P. J. (2007). Annual changes in body mass and resting metabolism in captive Barnacle Geese (Branta leucopsis). J. Exp. Biol. 210: 1391-1397. 
Portugal, S. J., Thorpe, S. K. S., Green, J. A., Myatt, J. P. and Butler, P. J. (2009a) Testing the use/disuse hypothesis: pectoral and leg muscle changes in captive Barnacle Geese Branta leucopsis during wing moult. J. Exp. Biol. 212: 2403-2410.

Portugal, S. J., Green, J. A., Cassey, P., Frappell, P. B. and Butler, P. J. (2009b). Predicting the rate of oxygen consumption from heart rate in barnacle geese: effects of captivity and annual changes in body condition. J. Exp. Biol. 212: 2941-2948.

Portugal, S. J., Butler, P. J., Green, J. A. and Cassey, P. (2011a) Indications of phenotypic plasticity in moulting birds: captive geese reveal adaptive changes in mineralisation of their long bones during wing moult. J. Ornithol. 152: 1055-1061.

Portugal, S. J., Green, J. A., Piersma, T., Eichhorn, G. and Butler, P. J. (2011b). Energy stores enable flightless moulting geese to maintain cryptic behaviour. Ibis. 153: 868-874.

Portugal, S. J., Green, J. A., White, C. R., Guillemette, M. and Butler, P. J. (2011c). Wild geese do not increase flight behaviour prior to migration. Biol. Lett. 8: 469-472.

Portugal, S.J., White, C.R., Green, J.A. \& Butler, P.J. (2019a) Flight feather moult drives minimum daily heart rate in wild geese. Biol. Lett. 14: 20180650.

Portugal, S.J., White, C.R., Frappell, P.B. \& Butler, P.J. (2019b) Impacts of "supermoon" events on the physiology of a wild bird. Ecol. Evol. 9: 7974-7984.

Portugal, S. J., Quinton, K., Isaac, R. \& Reynolds, S. J. (2010) Do captive waterfowl respond to the flightless period of wing moult in the same manner as their wild counterparts? Journal of Ornithology. 151: 443-448.

Portugal, S. J. (2008) Ecophysiological aspects of the annual cycle of barnacle geese, branta leucopsis. Thesis. University of Birmingham.

Robbins, C. T. (1993). Wildlife Feeding and Nutrition. Academic Press, San Diego, CA. Sjöberg, K. (1986). The flightless period of free-living male Teal Anas crecca in northern Sweden. Ibis. 130: 164-171.

Speakman, J. R. (1997). Doubly Labelled Water: Theory and Practise. Chapman and Hall, London. 
Speakman, J. R. (2001). Body composition analysis of animals. A handbook of nondestructive methods. Cambridge University Press, Cambridge.

Speakman, J. R., Visser, G. H., Ward, S. and Król (2001). The isotope dilution method for the evaluation of body composition. Pp. 56 - 98 in J. R. Speakman, ed. Body Composition Analysis of Animals. Cambridge University Press, Cambridge.

Turcek, F. J. (1966). On plumage quality in birds. Ekol. Pol. 14, 617-633.

Van der Graaf, A. J., Stahl, J., Veen, G. F., Havinga, R. M. And Drent, R. H. (2007).

Patch choice of avian herbivores along a migration trajectory - From temperate to Arctic. Basic. Appl. Ecol. 8: 354-363.

Van der Jeugd, H. P, Gurtovaya, E., Eichhorn, G., Litvin, K. Y., Minneev, O. Y. and van Eerden, M. (2003). Breeding barnacle geese in Kolokova Bay: number of breeding pairs, reproductive success and morphology. Polar Biol. 26 (11): 700-706.

Wetering, Van, D. and Cooke, F. (1999). Body weight and feather growth of male barrow's goldeneye during wing moult. Condor. 102: 228-231.

Woolfenden, G. E. (1967). Selection for a delayed simultaneous wing molt in loons (Gaviidae). Wil. Bull. 79 (4): 416-420.

Witter, M.S. and Cuthill, I.C. (1993). The ecological costs of avian fat storage. Phil. Trans. R. Soc. Lond. B. 340: 73-92.

Young, D. A. and Boag, D. A. (1982). Changes in physical condition of male mallards (Anas platyrhynchos) during moult. Can. J. Zool. 60: 3220-3226.

Zar, J. H. (1984). Biostatistical Analysis, $2^{\text {nd }}$ edn. Prentice Hall International, Englewood Cliffs, NJ. 